\title{
Role of the sympathicoadrenal system in the hemodynamic response to exercise in $\operatorname{dog} s^{1}$
}

\author{
EDMUNDO ASHKAR, ${ }^{2}$ JUAN J. STEVENS, ${ }^{3}$ \\ AND BERNARDO A. HOUSSAY \\ Instituto de Biologia y Medicina Experimental, Buenos Aires, Argentina
}

\begin{abstract}
Ashrar, Edmundo, Juan J. Stevens, and Bernardo A. Houssay. Role of the sympathicoadrenal system in the hemodynamic response to exercise in dogs. Am. J. Physiol. 214(1): 22-27. 1968. - Twelve dogs that ran well on a motor-driven treadmill were vagotomized and sympathectomized from $T_{1}-T_{7}$ plus $\mathrm{L}_{2}-\mathrm{L}_{6}$ and subjected to either unilateral adrenalectomy and contralateral adrenal demedullation $(\mathrm{SN}-\Lambda)$ or denervation of cranial mesenteric and common hepatic arteries (SN-MH). After recovery, cardiac output determinations (direct Fick) and continuous recording of mean aortic blood pressure, heart rate, and oxygen consumption were made at rest and during exercise at $7.5 \mathrm{~km} / \mathrm{hr}-10 \%$ gradient. Heart rate increased from 113 to 126 beats/min in the medulloadrenalectomized dogs and from 98 to 147 beats/min in dogs with hepatomesenteric denervation. Mean blood pressure did not vary substantially with exercise in either series of animals, averaging at rest $89 \mathrm{~mm} \mathrm{Hg}$ in dogs with adrenal medullectomy and 128 $\mathrm{mm} \mathrm{Hg}$ in dogs with intact adrenals. The resting cardiac index was similar in both groups (2.61 liters $/ \mathrm{min}$ per $\mathrm{m}^{2}$ ) and increased about $200 \%$ during exercise in medulloadrenalectomized animals as compared with $330 \%$ in dogs with hepatomesenteric denervation. During exercise, energy cost was essentially similar although peripheral resistance decreased about $75 \%$ in both groups.
\end{abstract}

autonomic denervation; exercise and hemodynamics; sympathicoadrenal systcm during excrcise; heart dencrvation and exercise; autonomic control of circulation

I

$I_{N}$ PREVIOUS INVESTIGATIONS from this laboratory, it has been shown that a marked limitation of several circulatory functions takes place in the exercising conscious vagotomizcd dog with complctc or extensive removal of the sympathetic chains $(2,3)$. Thus, during muscular work, the range of cardiac acceleration was restricted to very narrow limits, a decrease in blood pressure also being observed. However, when sympathetic ablation

Received for publication I May 1967.

1 This investigation was supported, in part, by funds received from Public Health Service Research Grant 5-R01-AM08307-07.

2 Established Career Investigator, National Council for Technical and Scientific Research, Buenos Aires, Argentina.

3 Postdoctoral trainee in cardiovascular physiology. was made leaving the lower thoracic level intact $\left(T_{7}-T_{12}\right)$ (in order to spare the innervation of the mesenteric organs and adrenal glands) the hemodynamic response was greatly improved being fairly similar to that of the normal dog (I).

Substantial evidence exists that the sympathicoadrenal system is involved in the circulatory response to sevcral stressing agents such as anesthesia, fright, emotional factors, hypoxia, hypotension, and also muscular activity, and plays a relevant role in maintaining a normal cardiovascular function. Also, circulating catecholamines can influence both cardiac and smooth muscle fibers of the resistance vascular bed, increasing heart rate and eliciting constrictor effects $(4,9,14,17-19,21,25)$. Furthermore, there are indications that during exercise, substances released from the adrenal medulla can act at a distance to stimulate cardiovascular effectors $(4,7,20,26)$. Nevertheless, such substances are reported to induce less effective vascular responses than those determined by direct sympathetic innervation of blood vessels (9).

In order to delineate the function of the two main interacting factors at the splanchnic level which could have played a role in the hemodynamic changes elicited by exercise in the denervated dog, experiments were conducted to evaluate the significance of the innervation of the mesenteric vascular bed and of the adrenal medullary hormones on the cardiovascular response to exercise.

\section{METHODS}

Experiments were carried out in 12 mongrel dogs of cither scx wcighing $6-16.5 \mathrm{~kg}$ which werc prepared and studied as reported in earlier papers $(1,3)$.

All animals were carefully trained to perform standard exercise on a motor-driven treadmill at $7.5 \mathrm{~km} / \mathrm{hr}-10 \%$ gradient. Dogs were only chosen for surgery after having performed at least ten 30 -min trials of exercise, freely and unleashed, over a period of several days.

They were then separated in two groups according to to the following surgical program:

Group $S N-A$, medulloadrenalectomized ( 6 dogs). One-stage removal of both thoracic sympathetic chains from $T_{1}-T_{7}$, with right thoracic vagotomy and bilateral lumbar sympathectomy, was performed as previously described 
$(1,2)$. Surgery was completed with left adrenal medullectomy. Seven days later the right adrenal gland was removed and the left vagus nerve and left carotid artery were explanted subcutaneously into a skin tube in the neck. Postoperative care consisted of a single supporting dose of $20 \mathrm{IU}$ of ACTH, $3 \mathrm{mg}$ of cortisone, and $1.5 \mathrm{mg}$ of Doca. Both water and saline were given ad lib.

Group $S N-M H$, hepatomesenteric denervation $(6$ dogs). In these animals, removal of the thoracic $\left(\mathrm{T}_{1}-\mathrm{T}_{7}\right)$ and lumbar $\left(\mathrm{L}_{1}-\mathrm{L}_{6}\right)$ sympathetic chains and right vagotomy were performed as above. Thereafter, denervation of the cranial mesenteric artery was carried out by extirpation of the cranial mesenteric ganglion and severance of the branches that constitute the corresponding perivascular plexus, which was also removed together with the aorticorenal and splanchnic ganglia. The common hepatic artery was similarly denervated by removal of the surrounding connective tissue containing the perivascular nerve plexus. In this manner, the sympathetic nerve supply to the abdominal organs (large intestine, proximal

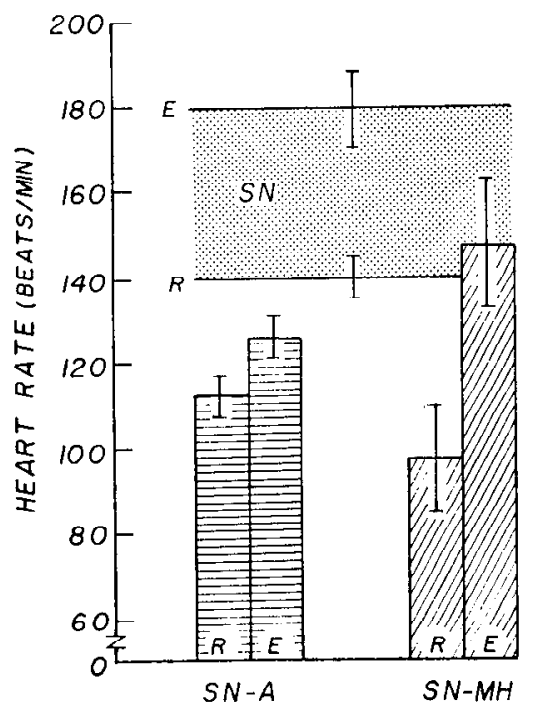

FIG. 1. Comparison of heart-rate values at rest and during the last minute of exercise in dogs with chronic cardiopulmonary denervation in which mesenteric innervation and the sympathicoadrenal mechanism was left intact (SN, stippled area). Dogs after adrenal demedullation: SN-A, horizontal dash; or after hepatomesenteric denervation: $\mathrm{SN}-\mathrm{MH}$, oblique dash. R: rest (recumbent), E: exercise. Values are means \pm SE. colon, pancreas, duodenum, stomach, liver, gall bladder, cystic duct, and spleen) was eliminated. The adrenal glands were left intact and the carotid artery and left vagus nerve prepared as above.

All animals were studied on the 17th day after the first operation. Minor surgery in the neck under local anesthesia (procaine $2 \%$ ) prepared the dog for blood vessel cannulation and tracheal intubation. The left vagus nerve was severed in the neck and wounds carefully sutured to prevent bleeding. A dose of 330 IU sodium heparin $/ \mathrm{kg}$ body wt was given initially, and thereafter $330 \mathrm{IU}$ every hour.

Standard work consisted of a 10 -min bout of exercise cvery $50 \mathrm{~min}$ at $7.5 \mathrm{~km} / \mathrm{hr}-10 \%$ grade. Cardiac output was determined by the direct Fick method at rest and during the last $2 \mathrm{~min}$ of work. For this purpose, a no. $8 \mathrm{~F}$ radioopaque catheter was introduced into either jugular vein and its tip placed in the main pulmonary artery or in the right ventricle under pressure control. A similar catheter was introduced into the left carotid artery down to the aortic arch for pressure recording and sampling for blood gas assay.

During rest determinations and exercise, dogs breathed pure oxygen from a light bell spirometer connected by a potentiometric circuit to the recording system.

Blood pressure was monitored by means of a Statham model P23Gb pressurc transducer. Heart rate per 10 $\mathrm{sec}$ was counted from the pressure tracings and instant changes were also recorded with a tachometer. All recordings were simultaneously obtained with a multichannel photorecorder model PR7, Electronics for Medicine. Blood gas determinations and other procedures were as described previously $(1,3)$.

Statistical significance was evaluated with the Student $t$ test. Differences were considered significant if $P<0.05$.

\section{RESULTS}

The present paper deals with the experimental results obtained in two groups of dogs with cardiopulmonary denervation in which either the adrenal medullary component or the direct innervation to the mesenteric vascular bed had been left intact. The observed hemodynamic responses were compared with values obtained in a group of previously studied animals in which cardiopulmonary denervation had been performed as above,

TABLE 1. Percent change of cardiovascular functions elicited by exercise

\begin{tabular}{|c|c|c|c|c|c|c|c|c|c|}
\hline & \multicolumn{9}{|c|}{ Mesenteric Innervation and Sympathicoadrenal System Condition } \\
\hline & \multicolumn{3}{|c|}{ Intact $(\mathrm{SN})$} & \multicolumn{3}{|c|}{ Adrenal demedullation (SN-A) } & \multicolumn{3}{|c|}{ Hepatomesenteric denervation (SN-MH) } \\
\hline & Rest & Exercise & Increment & Rest & Exercise & Increment & Rest & Exercise & Increment \\
\hline Heart rate & $140 \pm 6$ & $179 \pm 9$ & +28 & $113 \pm 5$ & $126 \pm 5$ & +11 & $98 \pm 13$ & $147 \pm 15$ & +50 \\
\hline Cardiac index & $4.4 \pm 1.3$ & $11.6 \pm 1.6$ & +161 & $2.6 \pm 0.4$ & $8.1 \pm 0.5$ & +207 & $2.6 \pm 0.3$ & $11.0 \pm 1.1$ & +330 \\
\hline Stroke volume & $20 \pm 5$ & $39 \pm 6$ & +96 & $14 \pm 2$ & $34 \pm 3$ & +146 & $9 \pm 1$ & $26 \pm 5$ & +179 \\
\hline Mean blood pressure & $108 \pm 4$ & $131 \pm 5$ & +21 & $89 \pm 9$ & $95 \pm 6$ & +7 & $128 \pm 3$ & $128 \pm 3$ & 0 \\
\hline Total peripheral resistance & $2.2 \pm 0.5$ & $0.9 \pm 0.1$ & -61 & $2.2 \pm 0.4$ & $0.7 \pm 0.1$ & -66 & $3.4 \pm 0.5$ & $0.7 \pm 0.1$ & -80 \\
\hline
\end{tabular}

Tabulated values are arithmetic means $\pm \mathrm{sE}$. 
TABLE 2. Summary of hemodynamic changes in medulloadrenalectomized series

$(S N \cdot A)$ of dogs at rest and during exercise at $7.5 \mathrm{~km} / \mathrm{hr}-10 \%$ grade

\begin{tabular}{|c|c|c|c|c|c|c|c|}
\hline Dog No., Wt, Surface Area & Heart Rate/min & $\mathrm{O}_{2}$ Consumption, & $\begin{array}{l}\text { A-V Oxygen Diff, } \\
\text { ml/liter }\end{array}$ & $\begin{array}{l}\text { Cardiac Index, } \\
\text { liter } / \text { min per } \mathrm{m}^{2}\end{array}$ & $\begin{array}{c}\text { Stroke Volume, } \\
\mathrm{ml} / \text { beat }\end{array}$ & $\begin{array}{c}\text { Mean Aortic } \\
\text { Blood Press, } \\
\text { mm Hg }\end{array}$ & $\begin{array}{l}\text { Total Peripheral } \\
\text { Resistance, mm } \\
\text { Hg seg } \mathrm{m}^{2} \mathrm{ml}^{-1}\end{array}$ \\
\hline \multicolumn{8}{|l|}{$1,11.5 \mathrm{~kg}, 0.60 \mathrm{~m}^{2}$} \\
\hline Recumbent & 120 & 100 & 5.5 & 3.05 & 16 & 88 & 1.76 \\
\hline Exercise & 140 & 302 & 9.3 & 5.70 & 24 & 118 & 1.22 \\
\hline \multicolumn{8}{|l|}{$2,16.5 \mathrm{~kg}, 0.75 \mathrm{~m}^{2}$} \\
\hline Recumbent & 120 & 186 & 15.7 & 1.58 & 10 & 78 & 2.95 \\
\hline Fxercise & 145 & 900 & 11.4 & 10.60 & 54 & 75 & 0.60 \\
\hline \multicolumn{8}{|l|}{$3,11.5 \mathrm{~kg}, 0.58 \mathrm{~m}^{2}$} \\
\hline Recumbent & 115 & 70 & 6.7 & 1.80 & 10 & 105 & 3.50 \\
\hline Exercise & 125 & 590 & 12.9 & 8.00 & 35 & 130 & 0.98 \\
\hline Recumbent & 115 & & & & & 110 & \\
\hline Exercise & 130 & 780 & 13.9 & 9.70 & 43 & 110 & 0.68 \\
\hline Recumbent & 120 & & & & & 103 & \\
\hline Exercise & 125 & 620 & 11.9 & 9.00 & 42 & 105 & 0.70 \\
\hline \multicolumn{8}{|l|}{$4,11.0 \mathrm{~kg}, 0.54 \mathrm{~m}^{2}$} \\
\hline Recumbent & 150 & 115 & 10.0 & 2.00 & 8 & 65 & 1.95 \\
\hline Exercise & 160 & 520 & 12.7 & 7.60 & 25 & 73 & 0.58 \\
\hline \multicolumn{8}{|l|}{$5,9.5 \mathrm{~kg}, 0.53 \mathrm{~m}^{2}$} \\
\hline Recumbent & 110 & 105 & 6.0 & 3.30 & 16 & 99 & 1.80 \\
\hline Exercise & 135 & 480 & 12.1 & 7.50 & 29 & 84 & 0.67 \\
\hline Recumbent & 120 & 105 & 4.7 & 4.10 & 19 & 77 & 1.10 \\
\hline Exercise & 137 & 520 & 12.8 & 7.70 & 30 & 72 & 0.56 \\
\hline Receumbent & 130 & & & & & 89 & \\
\hline Exercise & 135 & 320 & 8.3 & 7.20 & 35 & 73 & 0.61 \\
\hline \multicolumn{8}{|l|}{$6,8.2 \mathrm{~kg}, 0.50 \mathrm{~m}^{2}$} \\
\hline Recumbent & 100 & 160 & 8.0 & 4.00 & 20 & 99 & 1.48 \\
\hline Exercise & 100 & 400 & 12.2 & 6.60 & 33 & 75 & 0.68 \\
\hline Recumbent & 110 & 160 & & & & 100 & \\
\hline Exercise & 120 & 320 & 8.9 & 7.20 & 30 & 90 & 0.75 \\
\hline
\end{tabular}
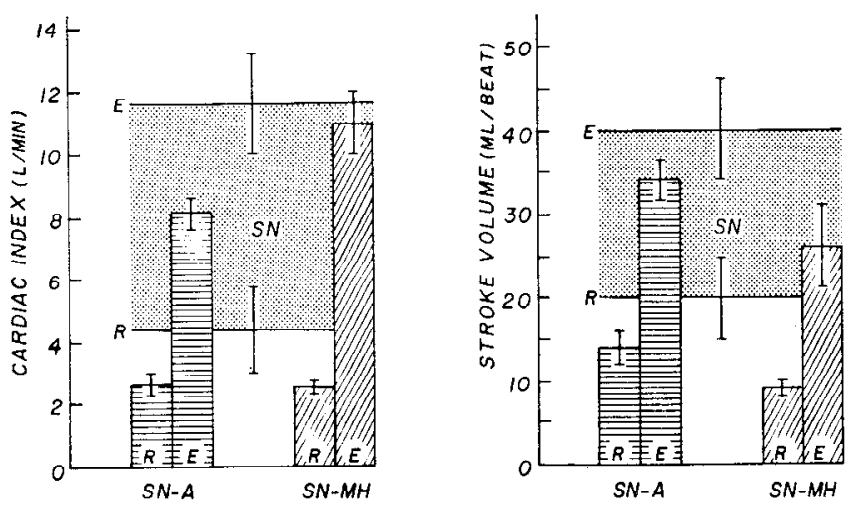

FIG. 2. Comparison of cardiac index (left panel) and of stroke volume (right panel) in the three considered groups. Symbols as in Fig. 1.

but sparing the sympathicoadrenal mechanism (and consequently with both splanchnic nerves and adrenal glands intact). These animals will be designated the reference (SN) group for both cxperimental series. ${ }^{4}$ Thus, group SN-A differed from $\mathrm{SN}$ in that the hormonal component was eliminated by unilateral adrenalectomy and contralateral adrenal demedullation. Conversely, $\mathrm{SN}-\mathrm{MH}$ dogs differed from the reference dogs in that the nervous component was suppressed by denervation of the hepatomesenteric bed.

${ }^{4}$ Data was taken from a previous paper with written permission of the editors.
Effects on heart-rate response to exercise. Figure 1 shows heart-rate values at rest and during the last minute of exercise in all three series. In this and subsequent figures, the horizontal stippled area represents the resting and exercise values of dogs which served as reference of both experimental groups (SN-A and SN-MH) which are depicted in separate paired columns.

As Fig. 1 and Tables 1-3 indicate, adrenal medullectomy restrictcd the degree of exercise tachycardia to very narrow limits, but this was not the case when the adrenal medullary component was spared as can be seen in the SN dogs and the animals in which hepatomesenteric denervation was performed. Although the average heart rate during exercise of the latter group (SN-MH) was lower than that of the reference animals, this difference was not significant. However, when comparison was made between reference and medullectomized groups, cardiac acceleration of the former was significantly higher $(P<0.001)$.

Cardiac output and stroke-volume changes during exercise. The left panel of Fig. 2 and Tables 1-3 show that the cardiac output (cardiac indcx) of dogs with either hepatomesenteric denervation or medulloadrenalectomy, averaged 2.60 liters $/ \mathrm{min}$ per $\mathrm{m}^{2}$ body surface. This value is similar to the predicted basal index (3.1 liters) but lower than that observed in the reference group (4.45 liters). This difference may be due to the higher resting heart-rate values of these dogs.

During exercise, cardiac output was lower in medullo- 
adrenalectomized than in SN dogs or in animals with hepatomesenteric denervation, although the wide scatter of these data obscured the significance of the observation. This situation also appeared to be reflected in the stroke-

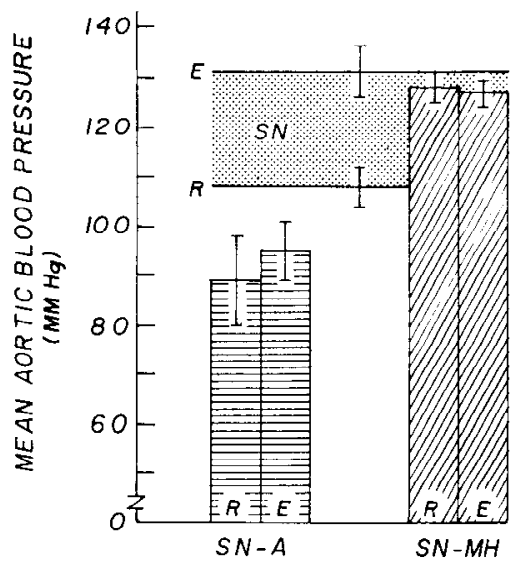

FIG. 3. Comparison of mean aortic blood pressure in the three considercd groups. Symbols as in Fig. 1. volume changes to muscular work as indicated in Fig. 2, right panel, and Tables 1-3. However, account must be taken of the fact that dogs which lacked their adrenal medulla showed negligible exercise tachycardia and therefore higher stroke-volume averages than their counterparts with hepatomesenteric denervation.

Effects on arterial blood pressure. Figure 3 and Tables 1-3 show that mean systemic blood pressure increased significantly from rest to exercise in the reference group $(P<0.001)$, while not undergoing important changes in either experimental series. In these series, the effect on blood pressure levels was dependent on whether the neural or hormonal factor had been suppressed.

Thus, in the SN-MH dogs (which had intact adrenal medulla), blood pressure levels were $44 \%$ higher than in dogs with medulloadrenal ablation (SN-A) $(P<$ $0.001)$. In addition, it is interesting to note that the higher blood pressure values of the former group were similar to those seen in the exercising $\mathrm{SN}$ animals.

Total peripheral resistance and oxygen uptake. The left panel of Fig. 4 and Tables 1-3 show that the over-all

TABLE 3. Summary of hemodynamic changes in dogs with hepatomesenteric denervation $(S N-M I I)$ at rest and during exercise at $7.5 \mathrm{~km} / \mathrm{hr}-10 \%$ grade

\begin{tabular}{|c|c|c|c|c|c|c|c|}
\hline Dog No., Wt, Surface Area & Heart Rate/min & 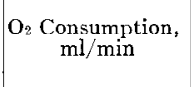 & $\begin{array}{l}\text { A-V Oxyen } \\
\text { Diff, ml/liter }\end{array}$ & $\begin{array}{l}\text { Cardiac Index, } \\
\text { liter/min per } \mathrm{m}^{2}\end{array}$ & $\begin{array}{l}\text { Stroke } \\
\text { Volume, } \\
\mathrm{ml} / \text { beat }\end{array}$ & $\begin{array}{l}\text { Mean Aortic } \\
\text { Blood Press, } \\
\text { mm Hg }\end{array}$ & $\begin{array}{l}\text { Total Peripheral } \\
\text { Resistance, mm } \\
\text { Hg seg m } \mathrm{ml}^{-1}\end{array}$ \\
\hline $1,6 \mathrm{~kg}, 0.36 \mathrm{~m}^{2}$ & & & & & & & \\
\hline $\begin{array}{l}\text { Recumbent } \\
\text { Excrcisc }\end{array}$ & $\begin{array}{l}115 \\
170\end{array}$ & $\begin{array}{r}42 \\
515\end{array}$ & $\begin{array}{r}4.6 \\
14.5\end{array}$ & $\begin{array}{l}2.50 \\
9.85\end{array}$ & $\begin{array}{r}8 \\
21\end{array}$ & 130 & $\begin{array}{l}3.12 \\
0.70\end{array}$ \\
\hline Recumbent & 130 & & & & & 130 & \\
\hline Exercise & 165 & 500 & 14.3 & 9.70 & 22 & 120 & 0.74 \\
\hline $2,7 \mathrm{~kg}, 0.40 \mathrm{~m}^{2}$ & & & & & & & \\
\hline Recumbent & 95 & 42 & 4.0 & 2.61 & 11 & 127 & 2.91 \\
\hline $\begin{array}{l}\text { Exercise } \\
\text { Recumbent }\end{array}$ & $\begin{array}{r}150 \\
90\end{array}$ & 420 & 11.1 & 9.50 & 25 & $\begin{array}{l}137 \\
147\end{array}$ & 0.87 \\
\hline $\begin{array}{l}\text { Kecumbent } \\
\text { Fxercise }\end{array}$ & 200 & 375 & 13.1 & 7.20 & 14 & $\begin{array}{l}147 \\
135\end{array}$ & 1.12 \\
\hline Recumbent & 85 & & & & & 127 & 1.12 \\
\hline Exercise & 175 & 518 & 12.3 & 10.70 & 24 & 141 & 0.79 \\
\hline Recumbent & 110 & & & & & 87 & \\
\hline Exercise & 160 & 518 & 13.0 & 10.10 & 25 & 109 & 0.64 \\
\hline $3,11.5 \mathrm{~kg}, 0.65 \mathrm{~m}^{2}$ & & & & & & & \\
\hline Recumbent & 180 & 46 & 4.4 & 1.60 & 6 & 128 & 5.62 \\
\hline Exercise & 220 & 880 & 10.4 & 13.10 & 39 & 140 & 0.64 \\
\hline Recumbent & 190 & & & & & 133 & \\
\hline Exercise & 230 & 880 & 10.3 & 13.10 & 37 & 140 & 0.64 \\
\hline $\begin{array}{l}4,7.4 \mathrm{~kg}, 0.40 \mathrm{~m}^{2} \\
\text { Recumbent }\end{array}$ & 76 & & & & & 115 & \\
\hline Exercise & 116 & 750 & 12.4 & 15.00 & 52 & 122 & 0.49 \\
\hline Recumbent & 72 & & & & & 137 & \\
\hline Exercise & 136 & 520 & 11.2 & 11.60 & 34 & 122 & 0.63 \\
\hline Recumbent & 72 & & & & & 126 & \\
\hline Exercise & 98 & 720 & 11.7 & 15.20 & 62 & 137 & 0.54 \\
\hline Recumbent & 84 & & & & & 130 & \\
\hline Exercise & 142 & 560 & 9.3 & 15.00 & 42 & 122 & 0.48 \\
\hline Recumbent & 70 & & & & & 130 & \\
\hline Exercise & 120 & 480 & 9.4 & 12.75 & 42 & 133 & 0.63 \\
\hline $\begin{array}{l}5,9.3 \mathrm{~kg}, 0.50 \mathrm{~m}^{2} \\
\text { Recumbent }\end{array}$ & 120 & 80 & & 2.95 & 12 & 125 & 2.52 \\
\hline $\begin{array}{l}\text { Recumbent } \\
\text { Exercise }\end{array}$ & 140 & 720 & 8.4 & 17.00 & 60 & 122 & 0.43 \\
\hline Recumbent & 130 & & & & & 128 & \\
\hline $\begin{array}{l}\text { Exercise } \\
6 \in m^{2}\end{array}$ & 150 & 800 & 9.5 & 16.80 & 56 & 118 & 0.42 \\
\hline $\begin{array}{c}\text { 6, } 6 \mathrm{~kg}, 0.36 \mathrm{~m}^{2} \\
\text { Recumbent }\end{array}$ & 92 & 55 & 5.0 & 3.22 & 10 & 147 & 2.72 \\
\hline Exercise & 155 & 380 & 10.2 & 9.40 & 24 & 128 & 0.82 \\
\hline
\end{tabular}



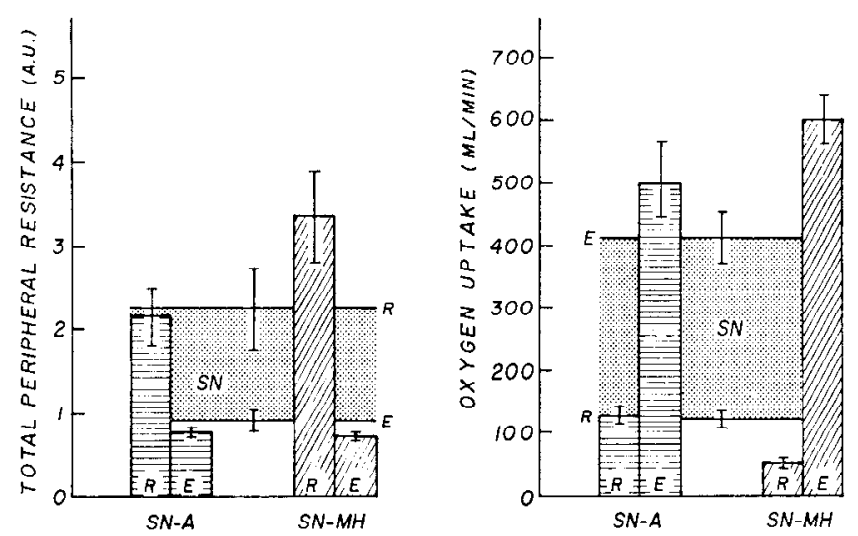

FIG. 4. Comparison of total peripheral resistance (left panel) and oxygen consumption (right panel) in the three considered series. Symbols as in Fig. 1.

peripheral resistance during exercise, expressed as the ratio of mean systcmic blood pressurc (in $\mathrm{mm} \mathrm{Hg}$ ) to cardiac index (in $\mathrm{ml} / \mathrm{sec}$ per $\mathrm{m}^{2}$ ) fell $75 \%$ to similar values in the three series.

In dogs in which the hormonal component had been spared (SN-MH), resting peripheral resistance was $55 \%$ higher than in animals with innervated hepatomesenteric bed (SN-A). Since the resting cardiac index was similar in both groups, the observed differences in blood pressure must be attributed to the corresponding differences in total peripheral resistance.

Right panel of Fig. 4 and Tables 2 and 3 show that average oxygen consumption during exercise in the reference dog was $413 \mathrm{ml} / \mathrm{min}(\mathrm{se} \pm 39$ ), $496 \pm 59$ $\mathrm{ml} / \mathrm{min}$ aftes adrenal demedullization, and $596 \pm 42$ $\mathrm{ml} / \mathrm{min}$ following hepatomesenteric denervation. No significance was found between series indicating that the energy cost for dogs of the three groups was essentially similar.

\section{DISCUSSION}

The hemodynamic pattern in the vagotomized dog with upper thoracic and lumbar sympathetic innervation removed following adrenal medullectomy differs from that following hepatomesenteric denervation in that systemic blood pressure is low and cardiac acceleration negligible following medullectomy whereas blood pressure is high and cardiac acceleration maintained following hepatomesenteric nerve exclusion.

These facts indicate that the enhanced vascular tone and the elevated cardiac acceleration rates are primarily linked to the adrenal medullary component. Therefore, the hormones from the adrenal medulla appear to play a dominant role.

If the acceleration in heart rate observed during exercise in the dog with cardiac denervation and the sympathicoadrenal system intact ( $\mathrm{SN}$ dogs) had been due to a direct action of norepincphrinc released at the sympathetic postganglionic nerve endings $(12,24,27,28)$, a similar response in heart rate should have been evidenced in the dog with adrenal demedullation. The failurc of dogs with adrenal demedullation to enhance cardio- acceleration and the marked acceleratory response in the dog with intact adrenals indicate that acceleration is not related to norepinephrine released at postganglionic nerve endings. This was so despite the fact that denervated hearts show supersensitivity to norepinephrine $(10,13)$.

The slight increase in cardiac acceleration in the medullectomized dog is similar to that seen in the exercising vagotomized-sympathectomized $\operatorname{dog}(2,3)$ and is in accordance with previous observations on cats with chronic cardiac denervation subjected to unilateral adrenalectomy and contralateral demedullation $(5,6)$, on chronic atropinized-sympathectomized $\operatorname{dogs}\left(\mathrm{T}_{1}-\mathrm{T}_{7}\right)$ following bilateral splanchnicectomy (25), or on chronic dogs with cardiac denervation after adrenal medulla inactivation (4).

Thus, in the animals reported in this study, the increase in heart rate can be primarily ascribed to the release of adrenal catecholamines $(16,21,23,29)$. No mechanism as yet can be described for the residual increase in heart rate seen during exercise in the denervated or medullectomized dog with cardiac denervation $(2,12)$.

The augmented blood pressure which is observed in the reference dogs (SN) during exercise, deserves further consideration. It did not occur in the dogs subjected to hepatomesenteric denervation and was not significant in the medullectomized animals. Whether the increase in blood pressure is due to the summation of the nervous and humoral factors of the sympathicoadrenal mechanism remains to be determined. However, the finding by Celander (9) that the adrcnal sympathetic secretory nerves, when appropriately stimulated, are capable of provoking "a clear cut reinforcement of the neural component which could be related to the medullary catechols" would harmonize with this posibility.

A possible explanation of the enhancement in vascular tone seen in dogs with adrenals intact, would be based on: a) the resulting supersensitivity of denervated vessels to catecholamines $(8), b$ ) the increased blood pressure during bilateral splanchnic nerve stimulation which was suppressed by adrenalectomy $(14), c$ ) the constriction of abdominal vessels and augmented release of adrenal catecholamines following splanchnic nerve stimulation $(11,21,22,26,28)$, and $d)$ the splanchnic nerves increased rate of firing under stress situations (15).

On the contrary, the effects of medullectomy or hepatomesenteric denervation on cardiac output and total peripheral resistance were of no significance as compared to those seen in the reference dog (SN). Howcver, a reduced cardiac output response to exercise in medullectomized dog is perhaps to be envisaged and, when added to the hemodynamic picture of these animals, could merit further studies.

From the present experiments it can be suggested that the observed cardiovascular response of dogs with cardiac denervation and sympathicoadrenal mechanism intact, was due rather to the adrenal medullary effects than to the direct neurogenic action on the abdominal vessels which was less evident. 


\section{REFERENGES}

1. AshKar, E. Circulatory changes during exercise in denervated dogs with intact splanchnic nerves. Acta Physiol. Lationam. 15: 351-356, 1965.

2. AshKar, E. Heart rate and blood pressure during exercise in dogs with autonomic denervation. Am. J. Physiol. 210:950$952,1966$.

3. Ashkar, E., and W. F. Hamilton. Cardiovascular response to graded exercise in the sympathectomized-vagotomized dog. Am. J. Physiol. 204: 291-296, 1963.

4. Campos, F. A. de M., W. B. Cannon, H. Lundin, and T. T. Walker. Some conditions affecting the capacity for prolonged muscular work. Am. J. Physiol. 87: 680-701, 1929.

5. Cannon, W. B., and S. W. Britton. Studies on the condition of activity in endocrine glands. XX. The influence of motion and emotion on medulliadrenal secretion. Am. J. Physiol. 79: 433-465, 1926-27.

6. Cannon, W. B., J. T. Lewis, and S. W. Britton. Studies on the conditions of activity in endocrine glands. XVII. A lasting preparation of the denervated heart for detecting internal secretion with evidence for accessory accelerator fibers from the thoracic sympathetic chain. Am. J. Physiol. 77: 326-352, 1926.

7. Cannon, W. B., J. R. Linton, and R. R. Linton. Conditions of activity in endocrine gland. XIV. The effects of muscle metabolites on adrenal secretion. Am. J. Physiol. $71:$ 153-162, 1924-25.

8. Cannon, W. B., And A. Rosenblueth. The Supersensitivity of Denervated Structures. New York: Macmillan, 1949, p. 23-139.

9. Celander, O. The control cxcrciscd by the sympathicoadrenal system. A quantitative study on blood vessels and other smooth muscle effectors in the cat. Acta Physiol. Scand. Suppl. 116: 1-132, 1954.

10. Cooper, T., V. L. Willman, and C. R. Hanlon. Drug responses of the transplanted heart. Diseases Chest 45:284-287, 1964.

11. Deal, C. P., Jr., and H. D. Green. Comparison of changes in mesenteric resistance following splanchnic nerve stimulation with responses to epinephrine and norepinephrine. Circulation Res. 4: 38-44, 1956.

12. Donald, D. E., and S. L. Samueloff. Exercise tachycardia not due to blood-borne agents in canine cardiac denervation. Am. J. Physiol. 211: 703-711, 1966.

13. Donald, D. E., And J. T. Shepherd. Supersensitivity to $l$ norepinephrine of the denervated sinoatrial node. Am. $J$. Physiol. 208: 255-259, 1965.
14. Elliot, T. R. The control of the suprarenal glands by the splanchnic nerves. J. Physiol., London 44: 374-409, 1912.

15. Gernandt, B., G. Lizjestrand, and J. Zotterman. Efferent impulses in the splanchnic nerves. Acta Physiol. Scand. 11: $230,1946$.

16. Goldfien, A., and W. F. Ganong. Adrenal medullary and adrenal cortical response to stimulation of diencephalon. Am. J. Physiol. 202: 205-211, 1962.

17. Grayson, J. H., and F. Lembeck. Soc. Number 14: Physiology of the Splanchnic Circulation. Monographs Physiol. Soc. (No. 14). London: Arnold, 1965, p. 32-56.

18. Green, H. D., and J. H. Kepchar. Control of peripheral resistance in major systemic vascular beds. Physiol. Rev. 39: 617-686, 1959.

19. Harakal, C., M. M. Reidenberg, R. W. Sevy, and E. A. OHLER. IIemodynamic effects of adrenal medullectomy in the dog. Am. J. Physiol. 210: 5-6, 1966.

20. Houssay, B. A., and E. A. Molinelli. Descarga de adrenalina provocada por la actividad muscular. Rev. Soc. Arg. Biol. 1: 125-143, 1925.

21. Malmejac, J. Activity of the adrenal medulla and its regulation. Physiol. Rev. 44: 186-218, 1964.

22. Marley, E., and G. I. Prout. Physiology and pharmacology of the splanchnic adrenal medullary junction. $J$. Physiol., London 180: 483-513, 1965.

23. OHokuzi, S. Effect of exercise on adrenaline and noradrenaline secretion of the adrenal gland in the dog. Tôhoku J. Exptl. Med. 88: 361-366, 1966.

24. Rosenblueth, A. The Transmission of Nerve Impulses at Neuroeffector Junctions and Peripheral Synapses. New York: Technology Press and Wiley, 1950, p. 68-73.

25. SamaAn, A. Muscular work in dogs submitted to different conditions of cardiac and splanchnic innervations. J. Physiol., London 83: 313-331, 1935.

26. Satake, Y. Secretion of Adrenaline and Sympathins. Tokyo: Nanzando, 1955, p. 23-121.

27. Vendsalu, A. Studies on adrenaline and noradrenaline in human plasma. Plasma concentrations of adrenaline and noradrenaline during muscular work. Acta Physiol. Scand. Suppl. 173: 57-69, 1960.

28. Von Euler, U. S. Noradrenaline. Springfield, Ill.: Thomas, 1956 , p. 259-284.

29. Wada, M., M. Seo, and K. Abe. Effect of muscular exercise upon epinephrine secretion from the suprarenal gland. Tôhoku J. Exptl. Med. 27: 65-86, 1935. 